\title{
Investigation of Health Management Domain Co-Authoring Activities through Social Network Analysis
}

\author{
S. Burak Bekaroglu \\ Faculty of Health Sciences \\ Marmara University \\ Maltepe, İstanbul, Turkey \\ Aysun Danayiyen \\ Faculty of Health Sciences \\ Okan University \\ Tuzla, İstanbul, Turkey \\ Zeynep Kavsur \\ Faculty of Health Sciences \\ Marmara University \\ Maltepe, İstanbul, Turkey \\ Oya Sancar \\ Faculty of Health Sciences \\ Istanbul Bilgi University \\ Dolapdere, İstanbul, Turkey
}

\begin{abstract}
The aim of this paper is to explore how health management departments' affiliation with faculties affects collaboration of authors. A social network-based collaborative model was established of 793 collaborations and a total of 203 publications used to make up the network. Discipline diversity index and university diversity index were developed. A regression model was used to investigate the extent to which ego network measures and institution, gender, and title changes contribute to changes in the indexes. With the models formed, the authors were tested according to their collaboration behaviors with different authors, different disciplines, different universities, their qualities, and ego network measures. Affiliation with health sciences increases interdisciplinary studies, whereas affiliation with management increases collaboration and university diversity, contributing to the release of a higher number of international publications. Preferred linking according to closeness, collaboration diversities decrease, thus an increase of constraint in reaching new information and resources is observed.
\end{abstract}

Keywords: health management department; co-authoring activities; social network analysis; discipline diversity; collaboration diversity; university diversity.

\section{Introduction}

In a scientific progress two facts must be mentioned in terms of contribution; the first one is competition, which, while forcing researchers to think outside of the acknowledged, ensures an inner control against inaccurate ideas. The second, on the other hand, is collaboration, which is defined as a combination of the studies of those that share information and have the same goals (Amabile et al., 2001). Collaboration is enabled to obtain new information and increase their visibility (Katz and Martin, 1997) as well as to share their knowledge, expertise and techniques and by this way accelerate their research process. Glanzel and Schubert,(2005) proved from a bibliometric point of view that collaboration can usually be analysed through co-authoring in scientific papers, and that semiotics is useful for investigating different aspects of collaboration. As connections between authors constituting the cooperative network are formed based on the authors' own decisions (reminders of the invisible hand theory), these networks reflect authors' collaboration development behavior (Çavusoglu and Türker, 2013). Co-authoring network research focuses from a macro perspective on the global nature of the networks (Newman, 2001; De Stefano et al., 2013; Tian et al., 2014). 
With a meso perspective, it can focus on investigation of subgroups (clusters or components) formed within the network (He et al., 2013) or with a micro perspective, it can focus on the characteristics of people involved in the network membership (Hansen, Shneiderman and Smith, 2010; Kretschmer, D. de B. Beaver, et al., 2015; Kumar, 2016). This article handles collaboration as co-authoring of a scientific publication.

The fields and types of publications, on which collaboration concentrates, as well as the properties of instructors that cooperate and the effects of these properties on collaboration were emphasized to reveal the academic collaboration network structure and the dynamic properties of health management departments. In Turkey, Health Management Departments can be established under both the Faculties of Health Sciences and Faculties of Management. In the study, a Health Management Department active under a Faculty of Management and a Health Management Department active under a Faculty of Health Sciences were selected from a social network analysis point of view, and the effect of being affiliated with different faculties in collaboration networks was investigated.

\section{Material and Methods}

One of the departments, whose network ties were investigated, was a Health Management Department (U2) active under the faculty of management, and the other was Health Management Department (U1) active under the Faculty of Health Sciences. Co-authored publications of instructors working in these departments published in the five-year period between the fall term of academic year 2011-2012, when U2 went into action, and the spring term of academic year 2014-2015 were used in order to form an academic collaboration network structure. A total of 793 academic collaboration and 203 co-authored publications constituted the dataset. In the study, co-authored international articles/bulletins, national articles/bulletins, and books/book sections of instructors are the publications utilized in the framework of academic collaboration.

The study aims to identify the differences that health management departments' affiliation with Faculties of Management or to Faculties of Health Sciences creates in co-authoring activities, and answers were searched for the following questions:

1. Are there any differences between the academic collaboration networks ties of two departments affiliated with different faculties?

2. Do authors in the networks of two departments that are affiliated with different faculties develop homophilia regarding quality and ego network measures in their collaboration preferences?

3. Do such qualities of authors as ego networks, institutions, and titles affect authors' collaboration with different authors, different fields, and different universities?

4. Do two departments that are affiliated with different faculties carry out co-publishing activities with different disciplines, different types of publication, and different universities?

Two types of criteria are used in social network analysis. The first is the structural measures of the network and the second is the ego measures, showing each actor's position in the network. Measures used in the study and the calculations there of are explained below.

Measures evaluated relating to the typological and dynamic structure of the networks in this study are listed below.

Density shows the percentage of all potential networks in a perfected network and is calculated by dividing the actual number of ties by the number of potential ties in the network (Prell, 2012).

Clustering coefficient shows the probability of an author in the network carrying out a co-authoring activity with two others; that is, the density of the triangles in a network (Çavusoglu and Türker, 2013). The clustering coefficient of networks showing small-world properties is bigger than that of analogous random networks, and the clustering coefficient tends to be five times bigger in scale-independent networks (Gürsakal, Tüzüntürk and Sert, 2014).

Average distance calculates the shortest path to be used in linking any two authors in the network (Abbasi, Altmann and Hossain, 2011). The average path length of a random network is longer than that of a scale-independent network (Goyal, Van der Leij and Moraga-González, 2006).

Diameter is the longest of all paths between all the author pairs in the network. The shorter the diameter of a network is the faster the distribution of information. Diameter in a random network is bigger than that of a scale-independent network (Çavusoglu and Türker, 2013).

Average Degree distribution of a network shows the distribution of ties the nodes have in any network and is interpreted as a measure of whether the network is homogenous. Variance of degree distribution is a measure of the centralization in the network (Goyal, Van der Leij and Moraga-González, 2006). 
Ego measures are used to analyze the roles and qualities of the authors in the network. Moreover, authors' academic collaboration behaviors were analyzed using such qualities as gender, title, institution, etc. Measures showing the position of actors in the network that are used in this study are listed below.

Degree is the scale of people that are directly bonded to each person. Degree centrality of a unit shows the number of ties (in this study, collaboration) that unit has ( $\mathrm{Al}$ and Sezen, 2012). For example, the degree of a person is " 5 " if s/he has five interactions (Güzeller, Eser and Aksu, 2016).

Closeness shows the close relation and affinity an actor has with other actors in the network. Close relations increase the possibility that people in the actor's network meet another people. Closeness centrality is the degree to which a unit can easily establish collaboration with other units, directly or indirectly (Al and Sezen, 2012) and can be accepted as the scale of the time it will take to transmit information from one actor to other accessible actors in the network (Seçkin Codal et al., 2016).

Betweenness shows the level of linking of a unit with units that are not directly bonded to each other. An actor's having a high degree of betweenness centrality is an indicator that the related actor will function as a bridge between disconnected actor sets (Abbasi and Altmann, 2002; Otte and Rousseau, 2002).

Clustering coefficient If there is a common neighbor between the actors, it gives that actor triple closure probability. It is two authors' probability of cooperating with a third in the co-authoring activity (Çavusoglu and Türker, 2013). If an actor has no neighbors or has only one neighbor, a value of " 0 " is assigned to it (Kaiser, 2008).

Constraint gives the measurement of the constraint exercised by the actors in the closed triplet on each other. In a sense, it is the reciprocal measure of social capital (Gürsakal, Tüzüntürk and Sert, 2014); therefore, constraint degrees of the authors that fill structural gaps are low (Tuncay and Özer, 2017).

Density is the measure of how often an actor uses his potential ties. The density of the network of an actor shows how closely bonded he is to his friends (Prell, 2012; Güzeller, Eser and Aksu, 2016).

The fact that an actor may produce different articles with the same author is taken into consideration in the calculation of collaboration diversity index. Calculated as an index between " 0 " and " 1 ", with the formula below subtracting recurring collaboration, collaboration diversity is the measure of the number of different authors with whom an author works (Li, Liao and Yen, 2013).

$$
\text { Collaboration diversity index }=\frac{\sum \text { coaut hor }{ }_{i}-\sum \text { duplicat } e_{i}}{\sum \text { relatio } n_{i}}
$$

While calculating discipline diversity index, the number of collaborations formed by an author in different disciplines is calculated by looking at the above collaboration diversity index, and discipline diversity is found by dividing the number of collaborations by the total number of ties.

$$
\text { Discipline diversity index }=\frac{\sum \text { codiciplin } e_{i}-\sum \text { duplicat } e_{i}}{\sum \text { relatio } n_{i}}
$$

While calculating university diversity index, the number of universities the authors an author cooperates with belong to is determined and divided by the number of ties. In this way, the number of universities the author is bonded to can be indexed.

$$
\text { University diversity index }=\frac{\sum \text { coinstitutio } n_{i}-\sum \text { duplicat } e_{i}}{\sum \text { relatio } n_{i}}
$$

Social network shows nodes and the ties between them with graphics. In this study, nodes show the authors, and the ties show academic collaboration established within the framework of co-authoring activity. A matrix showing how many times collaboration is established with the same person was prepared using the collaboration, matrix showing the authors taking part in co-authoring activity. Bimodal matrices of disciplines in which authors cooperate and universities cooperated with were established. These matrices were used while mapping the disciplines and universities with which collaborations are formed.UCINETT.644 for Windows (Borgatti, Everett and Freeman, 2002) was used in the calculation of network measures. Network diagrams were obtained using the NetDraw 2.160 (Borgatti, 2002) program. IBM-SPSS24.0 packaged software was used in the statistical analysis of data. In addition to definitive statistics, correlation analysis, chi-square tests, and multiple linear regression analysis were also used as statistical tests.

\section{Results}

Throughout the five-year period of assessment, a total of 107 co-authored publications were released in the U1 network, and 96 in the U2 network. Definitive statistics are given in Table 1. 


\begin{tabular}{|c|c|c|c|c|}
\hline \multirow{2}{*}{ Variables } & \multicolumn{2}{|c|}{ U1 } & \multicolumn{2}{|c|}{ U2 } \\
\hline & $\mathbf{n}$ & $\%$ & $\mathbf{n}$ & $\%$ \\
\hline N of authors & 16 & 59.25 & 11 & 40.75 \\
\hline Male authors & 6 & 54.54 & 5 & 45.45 \\
\hline Fermale authors & 10 & 62.50 & 6 & 37.50 \\
\hline N of co-authors & 103 & 51.24 & 98 & 48.76 \\
\hline Male co-authors & 41 & 42.26 & 56 & 57.73 \\
\hline Female co-authors & 62 & 59.61 & 42 & 40.38 \\
\hline Nofpublications & 107 & 52.70 & 96 & 47.29 \\
\hline Intemational article & 29 & 39.72 & 44 & 60.27 \\
\hline International proceeding & 20 & 41.66 & 28 & 58.33 \\
\hline National article & 14 & 70.00 & 6 & 30.00 \\
\hline National proceeding & 38 & 70.37 & 16 & 29.63 \\
\hline Book/book section & 6 & 75.00 & 2 & 35.00 \\
\hline Nof co-institution & 21 & 42.85 & 28 & 57.14 \\
\hline
\end{tabular}

Of the 793 collaborations making up the network, 551 (\%69.5) were formed by instructors at U1 network and 242 (\%30.5) by instructors at U2 network. $33.4 \%$ of these collaborations resulted in national bulletins, $30.4 \%$ in international articles, $21.7 \%$ in international bulletins, $13.2 \%$ in national articles, and $1.3 \%$ in publication of books and book sections, and a total of 203 publications were released.

Table 2 Structural network measures of the two data sources

\begin{tabular}{lcc}
\hline Variables & U1 & U2 \\
\hline N of collaboration & 551 & 242 \\
Network density & 0.018 & 0.021 \\
Clustering coefficient & 0.656 & 0.590 \\
Avg. Distance & 4.026 & 2.682 \\
Avg. Degree & 2.255 & 2.567 \\
Diameter & 7 & 5 \\
Degree centrality & 0.306 & 0.300 \\
\hline
\end{tabular}

In Table 2, although the network ties density of the U2 network is low (0.021), it is higher than that of the U1 (0.018) network. In the U1 (0.656) network, the clustering coefficient is higher than U2 (0.590), and authors show a higher tendency toward grouping. The size of the U2 network is 2 degrees lower than that of the U1 network. Authors can reach each other in 4 steps in the U1 network and in 2.7 steps in the U2 network. A structure with a high clustering coefficient ( $\mathrm{U} 1=0.66$; $\mathrm{U} 2=0.59)$, short average path lengths $(\mathrm{U} 1=4 ; \mathrm{U} 2=2.7)$, small diameters $(\mathrm{U} 1=7$; $\mathrm{U} 2=5)$, and degree distribution that is not normal indicates $(\mathrm{U} 1=2.3 ; \mathrm{U} 2=2.6)$ that the networks have the features of small-world networks. Therefore, in this study, the preferred attachment mechanism was assessed using the positions of the authors in the network in the next step.

\subsection{Actors' positions in network}

Actors' attributes, together with 1.5 ego networks, are in two different graphics below according to their degree centralities and taking their institutions into consideration.

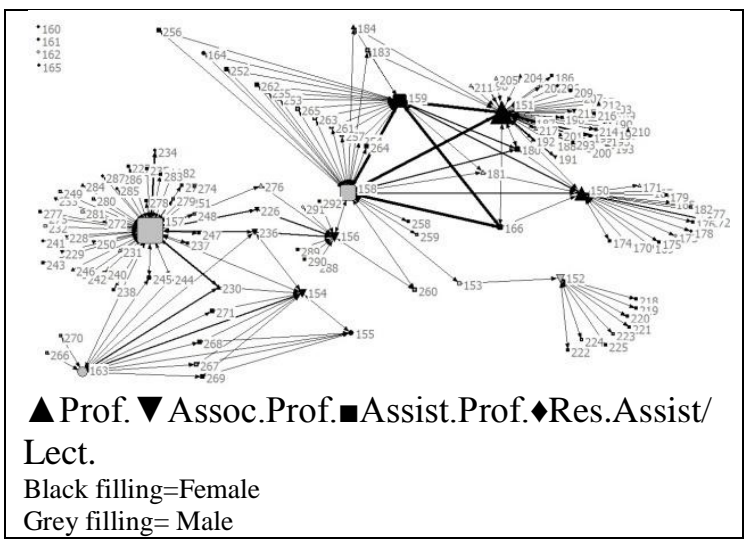

Fig. 1 $1_{\mathrm{a}}$ : U1 Academic Cooperation Network

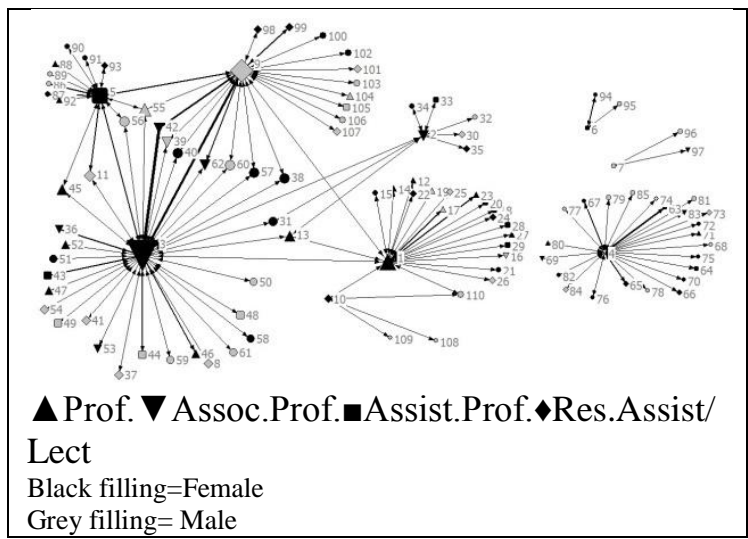

Fig. $1_{\mathrm{b}}$ : U2 Academic Cooperation Network

In the graphic, the sizes of the nodes have grown according to the degrees of the actors, and the thicknesses of the lines have increased according to the density of the collaboration network. Whereas authors that were focused on formed the nodes, authors that were cooperated with formed the second nodes. Triangles are indicators of clustering tendency and constraint. The subgroups formed were investigated with chi-square analysis in terms of homophilia. 
As a result of homophilia analysis by gender, it was observed that $67 \%$ of women in the U1 network formed academic collaborations with women, and $81 \%$ of men formed academic collaborations again with women $\left(\chi^{2}=12.616, p<0.001\right)$. In the U2 network, on the other hand, women formed $77 \%(\mathrm{n}=68)$ of their academic collaborations with men, and men formed $62 \%(n=94)$ of their academic collaborations again with men $\left(\chi^{2}=5.696, p<0.01\right)$.

As homophilia analysis according to title, it was found out professors preferred professors at a rate of $54 \%$ in terms of academic collaboration in the U2 network $\left(\chi^{2}=32.599, \mathrm{p}<0.001\right)$. In the U1 network, associate professors were observed to prefer the other group (students and sector employees) with $41 \%$ and the associate professor group with $38 \%$ $\left(\chi^{2}=49.280, \mathrm{p}<0.001\right)$. In the U2 network, assistant professors are in academic collaboration with the other group (students and sector employees) at a rate of $47 \%\left(\chi^{2}=10.941, p<0.001\right)$. In the U2 network, research assistants preferred associate professors for academic collaboration with a rate of $45 \%\left(\chi^{2}=19.729, \mathrm{p}<0.001\right)$.

In the U1 network, academic collaboration preferences of professors, associate professors, and research assistants according to title do not differ significantly.

The collaboration behaviors of actors are investigated according to 1.5 ego network criteria in terms of homophilia in Tables 3 and 4.

Table 3 Correlation between network measurement of author and co-author at U1.

\begin{tabular}{|c|c|c|c|c|c|c|}
\hline & \multirow[b]{2}{*}{ Author } & \multicolumn{5}{|c|}{ Co-author } \\
\hline & & 1. & 2. & 3. & 4. & 5. \\
\hline 1. & Degree & $-0.194 * * *$ & $0.093 *$ & $-0.135 * *$ & $-0.154 * * *$ & $0.231 * * *$ \\
\hline 2. & Closeness & $-0.185 * * *$ & $0.486 * * *$ & $-0.096 *$ & -0.049 & $0.116 * *$ \\
\hline 3. & Betweenness & $-0.094 *$ & -0.052 & $-0.156 * * *$ & $-0.087 *$ & $0.096 *$ \\
\hline 4. & Density & $0.162 * * *$ & -0.054 & $0.085 *$ & $0.183 * * *$ & $-0.207 * * *$ \\
\hline 5. & Constraint & $0.292 * * *$ & $-0.200 * * *$ & $0.200 * * *$ & $0.178 * * *$ & $0.334 * * *$ \\
\hline
\end{tabular}

A weak negative relationship $(\mathrm{r}=-0.194, \mathrm{p}<0.001)$ was identified between the degrees of the authors in the U1 network and degrees of the authors cooperated with, a moderate positive relationship $(r=0.486, p<0.001)$ between their closeness, a weak negative relationship $(\mathrm{r}=-0.156, \mathrm{p}<0.001)$ between their betweenness, a weak positive relationship $(r=0.183, p<0.001)$ between their densities, and a moderate positive relationship $(r=0.334, p<0.001)$ between their constraint.

Table 4 Correlation between network measurement of author and co-author at U2.

\begin{tabular}{llccccc}
\hline & & \multicolumn{5}{c}{ Co-author } \\
\cline { 2 - 6 } & Author & 1 & 2 & 3 & 4 & 5 \\
\hline 1. & Degree & $-0.128^{*}$ & $-0.272 * * *$ & $-0.156 *$ & $0.228 * * *$ & 0.118 \\
2. & Closeness & $-0.186^{* *}$ & $0.907 * * *$ & $-0.162 *$ & $-0.305 * * *$ & $0.156 *$ \\
3. & Betweenness & -0.040 & $-0.581 * * *$ & -0.070 & $0.280 * * *$ & 0.032 \\
4. & Density & $0.264 * * *$ & $-0.222 * * *$ & $0.257 * * *$ & -0.033 & $-0.308 * * *$ \\
5. & Constrain & $0.275 * * *$ & -0.026 & $0.276 * * *$ & -0.088 & $-0.290 * * *$ \\
\hline
\end{tabular}

$\mathrm{N}=242$.

$* \mathrm{p}<0.05 ; * * \mathrm{p}<0.01 ; * * * \mathrm{p}<0.001$

A weak negative relationship $(\mathrm{r}=-0.128, \mathrm{p}<0.05)$ was identified between the degrees of authors in the U2 network and those of the authors cooperated with, as well as a very strong positive relationship $(r=0.907, p<0.001)$ between their closeness and a weak negative relationship $(r=-0.290, \mathrm{p}<0.001)$ between their constraint.

Ego measures were used to analyze actors' roles and properties in the network. These measures provide information on the behaviors of actors forming collaboration together with the network structure. The relationship between authors' ego networks, institutions, genders, and titles was investigated through a Pearson correlation analysis. The Z-scores of variables expressed in different measurement units were taken to be able to compare such variables and transform continuous variables into new variables, the averages of which were 1 and standard deviations of which were 1 . 
The Z-scores are unit measurements that can be used to compare observations measured with different units, and therefore makes it possible to subject the qualities and ego criteria of actors forming the networks to correlation analysis. It is shown in Table 5(see below).

Table 5 Zero-order correlations between study variables.

\begin{tabular}{|c|c|c|c|c|c|c|c|c|c|c|c|c|c|}
\hline Variables & M & SD & 1 & 2 & 3 & 4 & 5 & 6 & 7 & 8 & 9 & 10 & 11 \\
\hline 1. Institution & 0.47 & 0.50 & & & & & & & & & & & \\
\hline 2. Gender & 0.66 & 0.48 & $0.180 *$ & & & & & & & & & & \\
\hline 3. Title & 2.68 & 0.950 & 0.018 & $0.264 * *$ & & & & & & & & & \\
\hline 4. Degree & 27.26 & 12.62 & $-0.258 * * *$ & $0.197 * *$ & 0.127 & & & & & & & & \\
\hline 5. Closeness & 417.66 & 93.90 & $-0.519 * * *$ & $-0.204 * *$ & $-0.161 *$ & $0.166 *$ & & & & & & & \\
\hline 6. Betweenness & 2476.27 & 1755.06 & $-0.699 * * *$ & -0.096 & 0.016 & $0.603 * * *$ & 0.003 & & & & & & \\
\hline 7. Density & 4.88 & 10.47 & $-0.150 *$ & -0.124 & $-0.294 * *$ & $-0.377 * * *$ & $0.163 *$ & $-0.226 * *$ & & & & & \\
\hline 8. Constrain & 0.05 & 0.10 & 0.022 & -0.080 & -0.369 ** & $-0.655^{* * * *}$ & $0.335 * * *$ & $-0.328 * * *$ & $0.764 * * *$ & & & & \\
\hline $\begin{array}{l}\text { 9. Cluster } \\
\text { coefficient }\end{array}$ & 0.11 & 0.13 & $-0.144 *$ & -0.137 & $-0.263 * *$ & $-0.349 * * *$ & $0.148 *$ & $-0.200 * *$ & 0.990 *** & $0.759 * * *$ & & & \\
\hline $10 \begin{array}{l}\text { Collaborate } \\
\text { diversity } \\
\text { index }\end{array}$ & 0.51 & 0.16 & $0.283 * * *$ & $0.270 * * *$ & $-0.174 *$ & -0.273 *** & $0.250 * * *$ & $-0.428 * * *$ & 0.093 & $0.169 *$ & 0.067 & & \\
\hline $\begin{array}{l}\text { 11. Discipline } \\
\text { diversity } \\
\text { index }\end{array}$ & 0.15 & 0.11 & 0.121 & $0.205 * *$ & $-0.308 * *$ & $-0.615 * * *$ & $0.376 * * *$ & $-0.373 * * *$ & 0.122 & $0.481 * * *$ & 0.098 & $0.683 * * *$ & \\
\hline $\begin{array}{l}\text { 12. University } \\
\text { diversity } \\
\text { index }\end{array}$ & 0.17 & 0.14 & $0.314 * * *$ & 0.046 & -0.081 & $-0.572 * * *$ & $0.220 * *$ & $-0.490 * * *$ & 0.116 & $0.474 * * *$ & 0.094 & $0.706 * * *$ & $0.715 * * *$ \\
\hline
\end{tabular}

Although degrees $(\mathrm{r}=-0.258, \mathrm{p}<0.001)$, closeness $(\mathrm{r}=-0.519 ; \mathrm{p}<0.001)$, betweenness $(\mathrm{r}=-0.699, \mathrm{p}<0.001)$, density $(\mathrm{r}=-0.150, \mathrm{p}<0.05)$ and clustering coefficients $(\mathrm{r}=-0.144, \mathrm{p}<0.05)$ of the $\mathrm{U} 1$ network are higher than those of the U2 network in the analysis, collaborative diversity $(r=0.283, p<0.001)$ and university diversity $(r=0.314, p<0.001)$ were lower.

When gender is assessed, where the collaborative diversity $(\mathrm{r}=0.270, \mathrm{p}<0.001)$ and discipline diversity $(\mathrm{r}=0.205$, $\mathrm{p}<0.01)$ of men is higher compared to that of women, the closeness measure $(r=-0.204, p<0.01)$ is lower.

When title relationships are examined, the higher the title, the lower the closeness $(\mathrm{r}=-0.161, \mathrm{p}<0.05)$, density $(\mathrm{r}=-0.294, \mathrm{p}<0.01)$, constraint $(\mathrm{r}=-0.369, \mathrm{p}<0.01)$, clustering coefficient $(\mathrm{r}=-0.263, \mathrm{p}<0.01)$, collaboration diversity $(\mathrm{r}=-0.174, \mathrm{p}<0.05)$ and discipline diversity $(\mathrm{r}=-0.308, \mathrm{p}<0.01)$.

When ego measures are assessed, as the degree increases, collaborative diversity $(r=-0.273, p<0.01)$, discipline diversity $(\mathrm{r}=-0.615, \mathrm{p}<0.001)$ and university diversity indexes $(\mathrm{r}=-0.572, \mathrm{p}<0.001)$ decrease. A weak positive relationship is present between closeness and collaborative diversity $(r=0.250, p<0.001)$, discipline diversity $(r=0.376$, $\mathrm{p}<0.001)$, and university diversity indexes $(\mathrm{r}=0.220, \mathrm{p}<0.05)$. As betweenness increases, collaborative diversity $(\mathrm{r}=-0.428, \mathrm{p}<0.001)$, discipline diversity $(\mathrm{r}=-0.373, \mathrm{p}<0.001)$ and university diversity indexes $(\mathrm{r}=-0.490, \mathrm{p}<0.001)$ decrease. Finally, a positive relationship appears between constraint and collaborative diversity $(r=0.169, p<0.05)$, discipline diversity $(\mathrm{r}=0.481, \mathrm{p}<0.01)$ and university diversity indexes $(\mathrm{r}=0.474, \mathrm{p}<0.01)$.

Six different models were set, two for each difference index.

\begin{tabular}{|c|c|c|c|c|c|c|c|c|c|c|c|c|}
\hline \multirow{4}{*}{$\begin{array}{l}\text { Variables } \\
\text { Institution }\end{array}$} & \multicolumn{12}{|c|}{ Dependent Variables } \\
\hline & \multicolumn{4}{|c|}{ Collaborate diversity index } & \multicolumn{4}{|c|}{ Discipline diversity index } & \multicolumn{4}{|c|}{ University diversity index } \\
\hline & \multicolumn{2}{|c|}{ Model 1} & \multicolumn{2}{|c|}{ Model 2} & \multicolumn{2}{|c|}{ Model 3} & \multicolumn{2}{|c|}{ Model 4} & \multicolumn{2}{|c|}{ Model 5} & \multicolumn{2}{|c|}{ Model 6} \\
\hline & 0.185 & $*$ & 0.502 & $*$ & 0.138 & & -0.852 & $* * *$ & 0.394 & $* * *$ & 0.107 & \\
\hline $\begin{array}{l}\text { Gender } \\
\text { Assist.Prof.a }\end{array}$ & 0.173 & $*$ & 0.367 & $* * *$ & 0.038 & & 0.195 & $* *$ & 0.003 & & 0.242 & $* * *$ \\
\hline Prof. & -0.162 & & 0.043 & & -0.363 & $* * *$ & -0.358 & $* * *$ & 0.079 & & 0.390 & $* * *$ \\
\hline Assoc.Prof. & 0.080 & & 0.180 & * & -0.197 & $*$ & -0.108 & & -0.138 & & 0.121 & \\
\hline Res.Assit./Lec. & 0.041 & & 0.109 & & -0.043 & & -0.187 & * & -0.074 & & -0.016 & \\
\hline Closeness & & & 0.687 & $* * *$ & & & -0.237 & * & & & 0.184 & \\
\hline Betweenness & & & -0.062 & & & & -0.969 & $* * *$ & & & -0.266 & \\
\hline Density & & & 0.309 & $*$ & & & -0.803 & $* * *$ & & & -0.490 & $* * *$ \\
\hline Constraint & & & -0.291 & $*$ & & & 0.840 & $* * *$ & & & 0.831 & $* * *$ \\
\hline$R^{2}$ & 0.167 & & 0.450 & & 0.136 & & 0.615 & & 0.128 & & 0.584 & \\
\hline$\Delta R^{2}$ & & & 0.283 & & & & 0.479 & & & & 0.455 & \\
\hline$F$ & 7.924 & $* * *$ & 17.559 & **** & 6.193 & $* * *$ & 34.190 & $* * *$ & 5.806 & $* * *$ & 30.080 & **** \\
\hline$\Delta \mathrm{F}$ & & & 24.812 & $* * *$ & & & 59.926 & $* * *$ & & & 52.791 & $* * *$ \\
\hline
\end{tabular}


In Table 6, there are six models in which collaborative, discipline and university diversities are dependent variables. In Model 1, which is set with collaborative diversity dependent variable, institution, gender, and titles were taken as control variables. These variables affect the dependent variable in a small but significant manner $\left(\mathrm{R}^{2}=0.167, \mathrm{~F}=7.924\right.$, $\mathrm{p}<0.001$ ). According to the institution control variable, U2 was observed to have a positive effect on collaborative diversity $(\beta=0.185, p<0.05)$. Moreover, according to the gender variable, men have a positive effect on collaborative diversity $(\beta=0.173, p<0.05)$. When closeness, betweenness, density, and constraint ego network measures are added to Model 2, which is set with the same dependent variable, the explanatory value of the model increased to $45 \%$ $\left(\Delta \mathrm{R}^{2}=0.283, \Delta \mathrm{F}=24.812, \mathrm{p}<0.001\right)$ and the biggest effect on the dependent variable was created by the closeness measures $(\beta=0.687, \mathrm{p}<0.001)$. Density, which follows closeness, is observed to have a positive effect on collaboration diversity $(\beta=0.309, p<0.01)$. However, constraint measures have a negative effect on the dependent variable $(\beta=-0.291$, $\mathrm{p}<0.01)$. Moreover, when ego network measures are added to the model, effects of the institution $(\beta=0.502, \mathrm{p}<0.01)$, gender $(\beta=0.367, \mathrm{p}<0.001)$ and associate professors $(\beta=0.180, \mathrm{p}<0.05)$ on the dependent variable increases. In Model 3, in which discipline diversity is the dependent measures, institution, gender, and titles, which are control variables, explain $14 \%$ of discipline diversity $\left(\mathrm{R}^{2}=0.136, \mathrm{~F}=6.193, \mathrm{p}<0.001\right)$. In Model 3, it was observed that compared to assistant professors, professors $(\beta=-0.363, \mathrm{p}<0.001)$ and associate professors $(\beta=-0.197, \mathrm{p}<0.05)$ have a negative effect on discipline diversity. When ego network measures, namely, closeness, betweenness, density, and constraint are added to Model 4, which was set with the same dependent variable, the explanatory value of the model increased to $62 \%$ in a statistically significant manner $\left(\Delta \mathrm{R}^{2}=0.479, \Delta \mathrm{F}=59.926, \mathrm{p}<0.001\right)$. When Model 4 is examined, it was found out that whereas betweenness $(\beta=-0.969, p<0.001)$ and density $(\beta=-0.803, p<0.001)$ had a strong negative effect on discipline diversity, closeness had a weak negative effect $(\beta=-0.237, \mathrm{p}<0.05)$ and constraint had a strong positive effect $(\beta=0.840$, $\mathrm{p}<0.001)$. Moreover, the model in question decreases the effect of institution $(\beta=-0.852, \mathrm{p}<0.001)$, gender $(\beta=0.195$, $\mathrm{p}<0.01)$ and research assistants/instructors $(\beta=-0.187, \mathrm{p}<0.01)$ on the dependent variable.

Finally, Models 5 and 6, in which university diversity index is the dependent variable, were set. The control variables of Model 5 are institution, gender, and title. Dependent variables explain 13\% of university discipline diversity in a significant manner $\left(\mathrm{R}^{2}=0.128, \mathrm{~F}=5.806, \mathrm{p}<0.001\right)$. The institution's effect on discipline diversity is observed to be in favor of the $\mathrm{U} 2$ network $(\beta=0.394, \mathrm{p}<0.001)$.

When ego measures, namely, closeness, betweenness, density, and constraint are included in Model 6, the explanatory value of the dependent variable increased significantly $\left(\Delta \mathrm{R}^{2}=0.455, \Delta \mathrm{F}=52.791, \mathrm{p}<0.001\right)$. According to Model 6 , density $(\beta=-0.490, p<0.001)$ was found to have a negative significant effect but constraint $(\beta=0.831, p<0.001)$ was found to have a positive significant preliminary effect on university diversity.

\subsection{Collaborative disciplines and universities and types of collaborative publications}

Authors formed collaboration with a total of 44 universities. These collaborations were formed in an informal manner for co-authoring activities and are visualized in Figure 2, believing that they are significant in terms of information sharing and production.

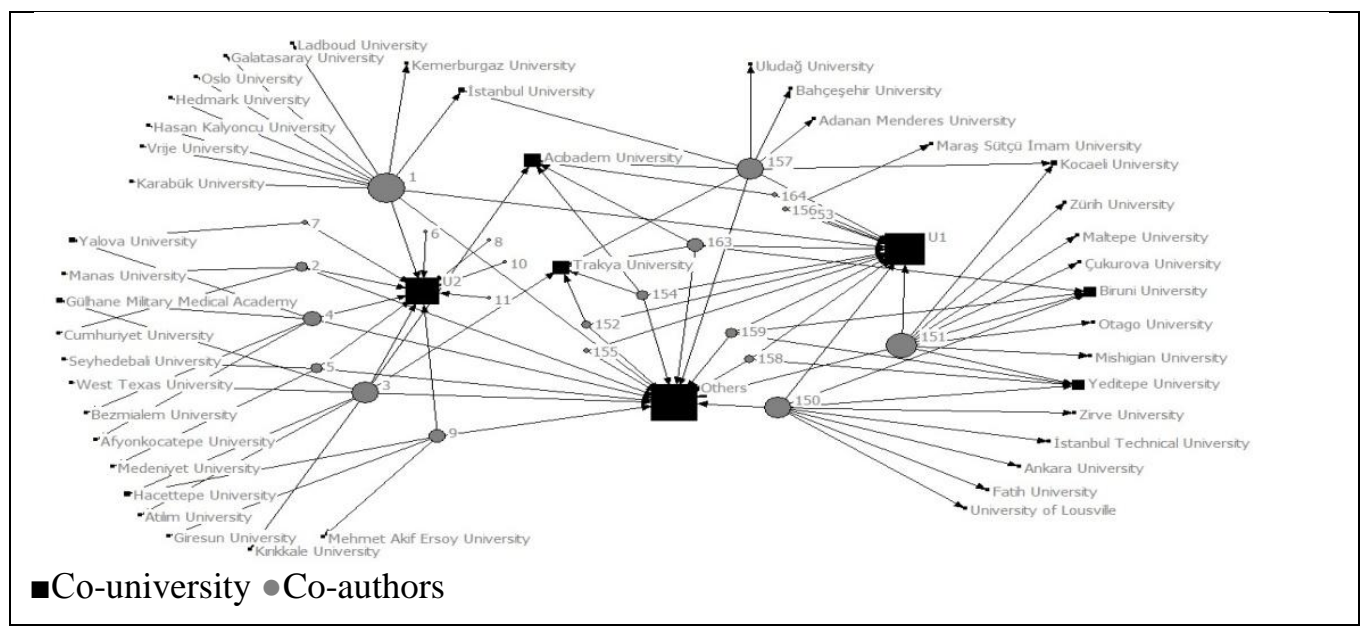

Fig. 2: Cooperated Universities

The sizes of the symbols show the degree of collaboration formed. Whereas collaborations were formed with 28 different universities in the U2 network, collaborations were formed with 21 universities in the U1 network. The most frequently cooperated universities in both networks are Acıbadem, Trakya, and Yeditepe Universities except for their university. 
The disciplines in which co-publications and differentiations in terms of institutions took place are shown in the graphics below.

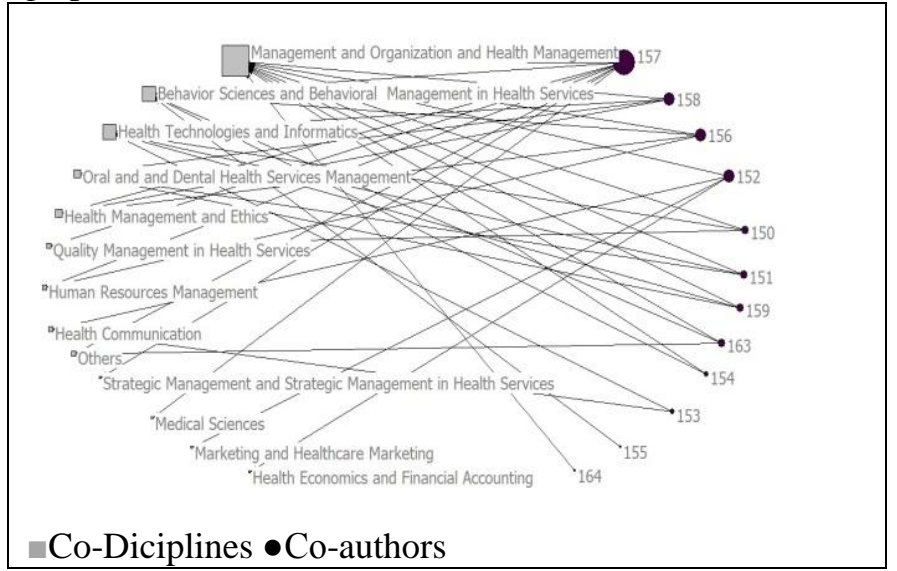

Fig. 3 a: U1 collaboration network across disciplines

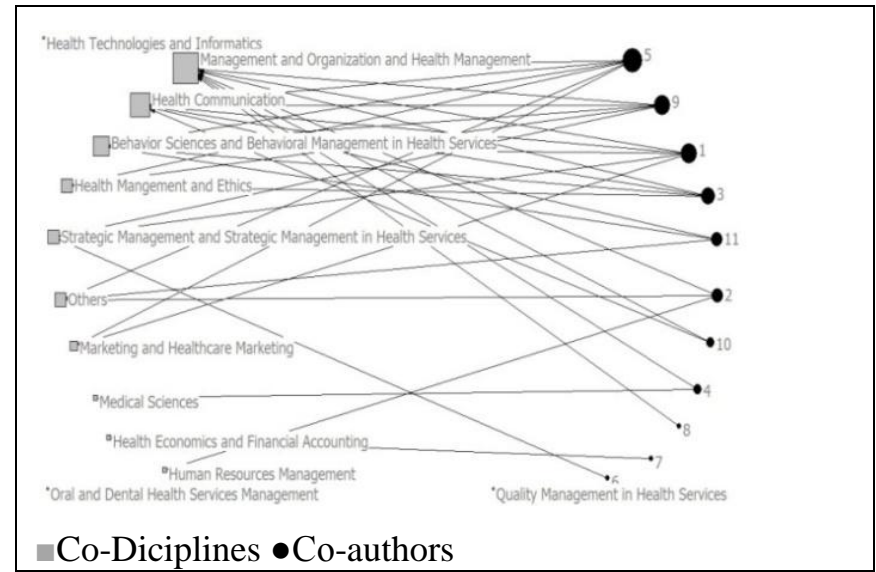

Fig. $3_{\mathrm{b}}$ : U2 collaborations network across disciplines

The ordering of the disciplines in which collaborations are formed is done according to the degree measures and sizes decrease, from the most frequently studied disciplines to the least frequently studied disciplines. The most frequent disciplines of collaboration between two networks are management and organization and health management disciplines in a similar way.

The ordering of collaboration between two institutions in other disciplines is different from the U2 network in that copublication studies in quality management in health services, health technologies and health IT $\left(\chi^{2}=17.721, p<0.000\right)$ and oral and dental health services disciplines $\left(\chi^{2}=13.491, \mathrm{p}<0.001\right)$ were not attempted at all in the U1 network. 57\% of 79 publications in the health management and management organization disciplines were produced in the U2 network $\left(\chi^{2}=4.853, \mathrm{p}<0.05\right) .93 \%$ of publications in the strategic management and management in health services were released by $\mathrm{U} 2$ network authors $\left(\chi^{2}=13.775, \mathrm{p}<0.001\right) .88 \%$ of the publications in the health communications discipline were published by $\mathrm{U} 2$ actors $\left(\chi^{2}=5.402, \mathrm{p}<0.05\right)$.

It was assessed whether there were any differences in the types of publications that produced the collaborative outcomes of the two faculties with differentiated collaborative field $60 \%$ of international articles $(n=73)$ were published as a result of collaboration of instructors of $\mathrm{U} 2.70 \%$ of national bulletins $(\mathrm{n}=54)$ were produced in the U1 network, and the difference is significant $\left(\chi^{2}=18.035, \mathrm{p}<0.001\right)$. A significant difference is not present in terms of national article and international bulletin and book publications.

\section{Discussion and Conclusions}

\subsection{Actors' positions in network}

In this study, it was observed that authors whose preferred attachment were investigated cooperated quickly, easily, and especially with (close) authors whom they had cooperated before. Compared to U2 network, authors of the U1 network form more direct collaboration, act as mediators, and tend towards easy collaboration with the authors they know and that are close. Closeness measures of authors cooperating in the U2 network show a positive and strong relationship as well. Coleman,(1990) asserts that social networks must be closed and that such essential features as collaboration and trust can only be developed in closed networks. Coleman states that information sharing will be easier if networks are closed, and that closed networks consisting of close, tight ties will reduce the risks to people when they trust each other. According to Li et al.,(2013), on the other hand, the closeness and betweenness measures of those cooperating with different academicians are high; however, they run the risk of losing their chance to cooperate with productive authors due to loss of trust. Actors filling the structural gap in academic network are stated to reach new information more easily (Demir and Taktak, 2011), form a larger number of collaborations (Li, Liao and Yen, 2013), have control of information dissemination and sharing (Ebadi and Schiffauerova, 2015) and are generally more productive (Abbasi and Altmann, 2002). Likewise, in this study, affecting ego measures rather than collaboration diversity is considered a closeness measure, but closeness was determined to affect discipline diversity studied negatively. The fact that actors in both networks investigated forms of academic collaboration with people that are close to them limits their study disciplines. Furthermore, although density, which shows actors' capacity to use their potential networks, increases collaboration diversity, it decreases discipline and university diversity. Contrary to expectations, betweenness measures do not increase actors' discipline diversity. This result suggests that people filling structural gaps in the network prefer to establish ties to publish in their fields of expertise and limit other actors in the network to study in their fields of 
expertise. In their study, Ebadi and Schiffauerova, (2015) found that those with high closeness are not important actors in the network as a whole, but that they are important in their own networks, as they are on the local shortcuts of information dissemination. In this study, as degree and betweenness increases as a result of preferred linking according to closeness, collaboration, discipline, and university diversities decrease, and thus an increase in constraint in reaching new information and resources is observed.

Many studies in the literature have investigated the relationship between such qualities as the gender, experience, etc. of actors forming the network and their network bond forming behaviors (Kretschmer and Kretschmer, 2013; Kumar, 2016). It was observed that in the U1 network, men and women preferred to form academic collaboration mostly with women. In the U2 network, on the other hand, collaboration with men was preferred. This difference might result from the faculty with which the department is affiliated. Whereas employees of the faculty of health sciences are mostly women, employees of the faculty of management are mostly men. In Malaysia, a similar study by Kumar,(2016) did not find any difference in terms of collaborative behavior, but there was a difference between men and women in terms of the number of publications and the number of men's publications were higher. However, Kreshmer et al., (2015)visualized that men's and women's collaboration networks are distinctly different from each other. Whereas men's collaboration and discipline diversity indexes were found to be significantly higher than that of women, the closeness measure of women was found to be significantly higher.

That is to say, in both networks, women carried out co-publishing activities by forming collaboration in more closed networks with a small number of people with whom they are in a close relationship. Men, on the other hand, take advantage of reaching new information as they increased collaboration diversity, discipline diversity, and university diversity by forming ties with more than one intermediary. In their study, Basak and Oztas, (2010) indicated that women in each occupational group had social capital with fewer intermediaries than men in the same occupational group.

The fact that filling structural gaps in terms of reaching new information and having control in scientific collaboration is more functional can be supported by these results. With respect to title, it was observed that only professors in the U2 network preferred professors for collaboration, and that title did not develop homophilia in the network in general. A similar comparison was made by Ebadi and Schiffauerova, (2015), who examined the effect of a study period after the doctoral degree on collaborative behavior and concluded that linking with productive researchers who can supervise the collaboration network and information flow well is useful in terms of productivity and reaching resources. Taking into consideration the fact that in order to hold a higher title you have to publish, it was observed in our study that authors tried to overcome their constraint by increasing their collaborative and discipline diversities, but in spite of that, although constraint and clustering coefficient increased as title is upgraded, collaboration and discipline diversities did not increase. In particular, the obligation to publish to hold a higher title was observed to guide authors to form collaborations with close people. It was evaluated that, instead of this, it might be useful to form collaborations with authors filling structural gaps in order to reach resources and new information and contribute to academic development. Members sharing different information produce new information layers by combining different information disciplines; thus, they create a higher level of creativity and increase quality (De Dreu and West, 2001; Wadhwa and Kotha, 2006). In this study, it was seen that the determinants of network actors' position were closeness, which restricted them in terms of access to new information and resources.

\subsection{Collaborative disciplines and universities and types of collaborative publications}

Although U1 network's closeness, betweenness, degree and clustering coefficient are higher than that of the U2 network, the U2 network's authors' university diversity and collaboration with different writers is higher. As distinct from the U1 network, no co-publication activities were carried out in the U2 network in the quality management in health services, health technologies, or health IT and oral and dental health disciplines at all. Furthermore, whereas the U1 network forms collaborations mostly in national publication production, U2 actors have mostly formed academic collaboration in international publications. Therefore, we can say that U2 actors, whose network measures are lower, are using the network more effectively by increasing collaborative and university diversity. It was observed that being a department in the faculty of health sciences increases interdisciplinary studies, whereas being a department in the faculty of management increases collaborative diversity and university diversity, contributing to the release of a higher number of international publications.

This study is the first of its kind in the health management domain. The study has focused on academic collaborative network structure, its effect on collaborative behaviors, and the effect of the faculty with which the department is affiliated on the collaborative diversity with people from different disciplines and universities; authors' performances and cooperative behaviors were not associated. Evaluation of performances of authors in the health management discipline, together with their collaboration, is suggested for future research. 


\section{List of abbreviations}

U2:Health Management Department Active Under The Faculty of Management

U1:Health Management Department Active Under The Faculty of Health Sciences.

\section{Availability of data and materials}

The datasets used and analyzed during the current study are available from the corresponding author upon reasonable requests.

\section{Lessons for Practice}

Betweenness and density restricts authors' discipline diversity.

Determinants of network actors' position were closeness.

Actors are restricted by closeness in terms of access to new information and resources.

Affiliation of health management department effects collaborative and university diversity.

Affiliation of health management department contributes to the release of a higher number of international publications.

\section{References}

Abbasi, A. and Altmann, J. (2002) 'On the Correlation between Research Performance and Social Network Analysis Measures Applied to Research Collaboration Networks'.

Abbasi, A., Altmann, J. and Hossain, L. (2011) 'Identifying the effects of co-authorship networks on the performance of scholars: A correlation and regression analysis of performance measures and social network analysis measures', Journal of Informetrics, 5(4), pp. 594-607. doi: 10.1016/j.joi.2011.05.007.

Al, U. and Sezen, U. (2012) 'Hacettepe üniversitesi bilimsel yayınlarının sosyal ă̆ analizi yöntemiyle değerlendirilmesi', Edebiyat Fakültesi Dergisi, 29(1), pp. 53-71.

Amabile, T. M. et al. (2001) 'Academic-practitioner collaboration in management research: A case of cross-profession collaboration', Academy of Management Journal, 44(2), pp. 418-431. doi: 10.2307/3069464.

Başak, S. and Öztaş, N. (2010) 'Güven Ağbağları, Sosyal Sermaye ve Toplumsal Cinsiyet.', Trust Networks, Social Capital and Gender., 12(1), pp. 27-56. Available at:

http://login.ezproxy.lib.umn.edu/login?url=http://search.ebscohost.com/login.aspx?direct=true\&AuthType=ip, uid $\& \mathrm{db}=$ buh $\& A N=57848103 \&$ site $=$ ehost-live.

Borgatti, S. (2002) 'NetDraw: Graph visualization software', Harvard: Analytic Technologies, p. SNA Analysis software.

Borgatti, S. P., Everett, M. G. and Freeman, L. C. (2002) 'UCINET 6 for Windows: Software for social network analysis (Version 6.102)', Harvard, ma: analytic technologies.

Çavuslu, A. and Türker, I. (2013) 'Scientific collaboration network of Turkey', Chaos, Solitons and Fractals: the interdisciplinary journal of Nonlinear Science, and Nonequilibrium and Complex Phenomena, 57, pp. 9-18. doi: 10.1016/j.chaos.2013.07.022.

Coleman, J. S. (1990) 'Foundation of Social Theory', Book, p. 993. doi: 10.2307/2579680.

Demir, H. and Taktak, F. (2011) 'Konumsal Veri Üzerine Sosyal Ăg Analizi (SAA): Afyonkarahisar Örneği', Harita Teknolojileri Elektronik Dergisi, 3(1), pp. 7-16. Available at: http://dergipark.ulakbim.gov.tr/hartek/article/view/5000090353.

De Dreu, C. K. W. and West, M. A. (2001) 'Minority dissent and team innovation: The importance of participation in decision making.', Journal of Applied Psychology, 86(6), pp. 1191-1201. doi: 10.1037/0021-9010.86.6.1191.

Ebadi, A. and Schiffauerova, A. (2015) 'How to become an important player in scientific collaboration networks?', Journal of Informetrics. doi: 10.1016/j.joi.2015.08.002.

Glänzel, W. and Schubert, A. (2005) 'Analyzing scientific networks through co-authorship', Handbook of Quantitative Science and Technology Research, (1963), pp. 257-276. doi: 10.1007/1-4020-2755-9.

Goyal, S., van der Leij, M. J. and Moraga-González, J. L. (2006) 'Economics: An Emerging Small World', Journal of Political Economy, 114(2), pp. 403-412. doi: 10.1086/500990.

Gürsakal, N., Tüzüntürk, S. and Sert, F. (2014) 'Sosyal ağ verilerinin kuvvet yasası olasılık dağılımına uygunluk analizi: Twiter örneği.', in 15. Uluslararası Ekonometrik Yöneylem ve İstatistik Sempozyumu Bildirileri Kitab1, pp. 464-482.

Güzeller, C. O., Eser, M. T. and Aksu, G. (2016) UCINNET ile sosyal ağ analizi.

Hansen, D., Shneiderman, B. and Smith, M. A. (2010) Analyzing Social Media Networks with NodeXL: Insights from a Connected World, Graduate Journal of Social Science. doi: 10.1016/B978-0-12-382229-1.00011-4. 
He, B. et al. (2013) 'Mining diversity subgraph in multidisciplinary scientific collaboration networks: A meso perspective', Journal of Informetrics, 7(1), pp. 117-128. doi: 10.1016/j.joi.2012.09.005.

Kaiser, M. (2008) 'Mean clustering coefficients: The role of isolated nodes and leafs on clustering measures for smallworld networks', New Journal of Physics, 10. doi: 10.1088/1367-2630/10/8/083042.

Katz, J. S. and Martin, B. R. (1997) 'What is research collaboration?', Research Policy, 26(1), pp. 1-18. doi: 10.1016/S0048-7333(96)00917-1.

Kretschmer, H., Beaver, D. deB., et al. (2015) 'Who is collaborating with whom? Part I. Mathematical model and methods for empirical testing', Journal of Informetrics, 9(2), pp. 359-372. doi: 10.1016/j.joi.2015.01.004.

Kretschmer, H., Beaver, D. de B., et al. (2015) 'Who is collaborating with whom? Part II. Application of the methods to male and to female networks', Journal of Informetrics. doi: 10.1016/j.joi.2015.01.009.

Kretschmer, H. and Kretschmer, T. (2013) 'Who Is Collaborating with Whom in Science? Explanation of a Fundamental Principle', Social Networking, 02(03), pp. 99-137. doi: 10.4236/sn.2013.23011.

Kumar, S. (2016) 'Effect of gender on collaborative associations of researchers in Malaysia', The Electronic Library. doi: 10.1108/EL-09-2014-0162.

Li, E. Y., Liao, C. H. and Yen, H. R. (2013) 'Co-authorship networks and research impact: A social capital perspective', Research Policy. doi: 10.1016/j.respol.2013.06.012.

Newman, M. E. J. (2001) 'The structure of scientific collaboration networks', Proceedings of the National Academy of Sciences of the United States of America, 98(2), pp. 404-409. doi: 10.1073/pnas.021544898.

Otte, E. and Rousseau, R. (2002) 'Social network analysis: a powerful strategy, also for the information sciences', Journal of Information Science, 28(6), pp. 441-453. doi: 10.1177/016555150202800601.

Prell, C. (2012) Social network analysis: history, theory \& methodology, Sage. Available at: http://trove.nla.gov.au/work/159412501?q=christina+prell+social+network+analysis\&c=book\&sort=holdings+ desc\&_=1383102366170\&versionId=176795286.

Seçkin Codal, K. et al. (2016) 'Sosyal Ağ Türlerinin Karşılaştırılmasına İlişkin Bir Ağ Analizi A Network Analysis Related To The Comparison Of Social Network Types Öz’, AIBU Journal of Social Sciences, 1616(16), pp. $143-158$.

De Stefano, D. et al. (2013) 'The use of different data sources in the analysis of co-authorship networks and scientific performance', Social Networks. doi: 10.1016/j.socnet.2013.04.004.

Tian, S. W. et al. (2014) 'Evolution model for scientific collaboration network with local-world information', Journal of China Universities of Posts and Telecommunications. doi: 10.1016/S1005-8885(14)60281-8.

Tuncay, S. S. and Özer, P. S. (2017) 'Asil-vekil ilişkilerinin kültürel bağlamda sosyal ağ kuramı çerçevesinde sosyal ağ analizi kullanılarak incelenmesi', Journal of Business Research, 9(2), pp. 478-510.

Wadhwa, A. and Kotha, S. (2006) 'Knowledge creation through external venturing: Evidence from the telecommunications equipment manufacturing industry', Academy of Management Journal, 49(4), pp. 819835. doi: 10.5465/AMJ.2006.22083132. 